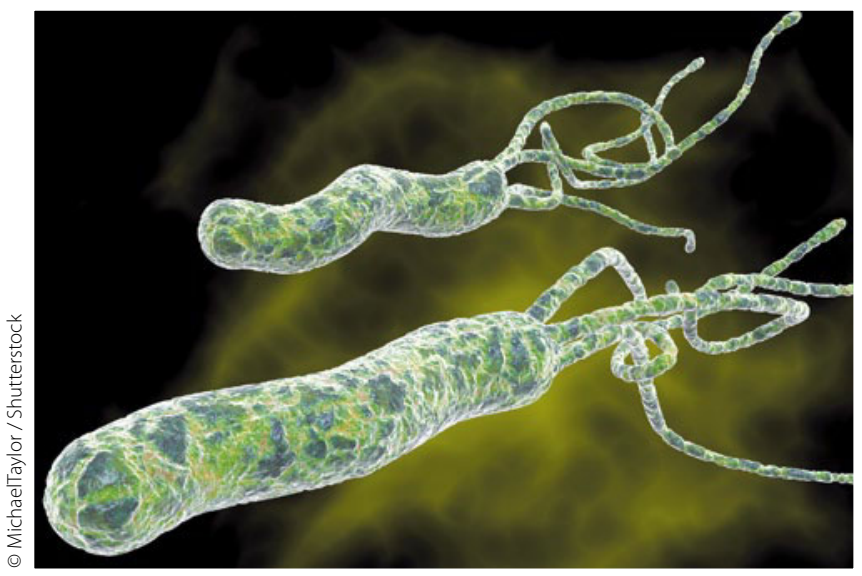

H. pylori macht nicht nur Magengeschwüre, sondern verändert auch die Eigenschaften des Zervikalschleims.

\section{Verursacht Helicobacter pylori Infertilität?}

\author{
Infektionen mit Helicobacter pylori sind sehr häufig. \\ Neuere Studien weisen auf einen möglichen \\ Zusammenhang zwischen dem Nachweis von IgG- \\ Antikörpern gegen dieses Bakterium und einer \\ sekundären Infertilität hin.
}

— Eine bekannte Ursache für Infertilität ist das Vorhandensein von sekretorischem IgA im zervikalen Mukus, das mit Strukturen auf den Spermien reagieren kann und so deren Beweglichkeit hemmt. Auf den Spermien befinden sich Antigene, die immunologisch einigen mikrobiellen Erregern ähneln und deshalb immunologische Kreuzreaktionen initiieren können.

In der vorliegenden Studie aus Italien prüften Autoren die Assoziation von IgG-Antikörpern gegen Helicobacter pylori (AntiH) im Serum und im zervikalen Mukus bei 67 Frauen mit einer idiopathischen Infertilität. Zudem wurde der Effekt dieser Antikörper auf die Eigenschaft des Zervikalschleims für die Passierbarkeit durch Spermien untersucht.

Die Messung von AntiH in Serum und Mukus erfolgte mittels eines kommerziellen Tests. Die Penetrationsfähigkeit der Spermien wurde in einem vereinfachten Objektträgertest bei 15 Zervikalschleimproben von AntiH-positiven sowie bei 15 AntiH-negativen Proben als Kontrollen vorgenommen.

Es zeigte sich eine signifikante positive Korrelation zwischen den Konzentrationen von AntiH-IgG im Serum und im Mukus ( $r=0,93 ; p<0,00001)$. Die Untersuchung des Mukus der AntiH-positiven Frauen ergab eine eindeutig gestörte Penetrationsfähigkeit der Spermien im Objektträgertest.
Die Autoren folgern, dass auch Helicobacter pylori zu den infertilitätsverursachenden Erregern gerechnet werden muss. Daher sollte bei der Abklärung einer Infertilität eine serologische Untersuchung der Frauen auf Anti-HIgG erfolgen.

- G. Ambrosini et al.

Anti-Helicobacter pylori antibodies in cervical mucus: a new cause of infertility. Eur. J. Obstet. Gynecol. Reproduct. Biol. 155 (2011) 157-160

\section{Kommentar}

Nach Schätzungen sind über 50\% der Weltbevölkerung mit Helicobacter pylori infiziert. Spezifisches lgG gegen diesen Keim lässt sich altersabhängig in 10-80\% der gesunden Normalbevölkerung nachweisen. Der Übertragungsweg der Infektion ist bis heute nicht restlos geklärt; am wahrscheinlichsten erscheint eine Schmierinfektion oder auch eine Mund-zu-Mund-Übertragung. Sollte sich der Zusammenhang von Antikörpern gegen dieses Bakterium und Infertilität in größeren Studien tatsächlich bestätigen, würde dies eine Vielzahl von unerfüllten Kinderwünschen erklären.

T. SCHWARZ = 